Rochester Institute of Technology

RIT Scholar Works

Theses

$12-6-1991$

\title{
The Biological basis of schizophrenia
}

Franz Sugarman

Follow this and additional works at: https://scholarworks.rit.edu/theses

\section{Recommended Citation}

Sugarman, Franz, "The Biological basis of schizophrenia" (1991). Thesis. Rochester Institute of Technology. Accessed from

This Thesis is brought to you for free and open access by RIT Scholar Works. It has been accepted for inclusion in Theses by an authorized administrator of RIT Scholar Works. For more information, please contact ritscholarworks@rit.edu. 


\section{ROCHESTER INSTITUTE OF TECHNOLOGY}

A Thesis Submitted to the Faculty of The College of Fine and Applied Arts in Candidacy for the Degree of MASTER OF FINE ARTS

The Biological Basis of Schizophrenia By

Franz Sugarman

Date: December 6, 1991 
Advisor: Glen Hintz

Date: $12-5-91$

Associate Advisor: Robert Wabnitz

Date:

Associate Advisor: Richard Doolittle

Date:

Philip Bornarth

Special Assistant to the Dean for Graduate Affairs: Joanne Szable

Date: $12 / 10 / 91$

Dean, College of Fine and Applied Arts: Peter Giopulos

Date:

I, Franz Sugarman, prefer to be contacted each time a request for production is made. I can be reached at the following address:

32 Anne Dr.

Schenectady, N.Y.

12303

phone: (518)355-0484

Date: 


\section{Contents}

FOREWORD

PG. 1

PART I: INTRODUCTORY

STATEMENTS

PG. 2

PART II: THEORY

PG. 6

PART III: MEDIA

PG. 20

REFERENCES

PG. 24

FOOTNOTES

PG. 26 


\section{FOREWORD}

A major obstacle which I have had to deal with both as I wrote this paper and designed my exhibit was the question, "who is this for?"

Five people will have to read and approve this paper. Five people had to view and judge my exhibit. Many more may wish to read my paper and review the pieces from my exhibit in order to decide whether to hire me or not. There are many more people who saw my exhibit, as well.

So, who was my exhibit for? Was it for the general public? Was it for my art professors? Was it for my science advisor? Was it for my prospective employers? Was it for the dean and assistant dean?

What I had to write about had to cover a wide range of material in what are effectively several different languages.

Few of the people who read this paper will really understand the scientific theory, despite my best efforts. I cannot cover several years of premedical and medical education which I have not even had myself in this paper. I hope the person with minimal medical knowledge will be able to comprehend the fundamental theory behind the biological basis of schizophrenia.

Non-artists may not be interested in my discussion of the media I chose.

Artists and non-artists alike, who do not use computers, may have little interest in my discussion of the computer software I used.

I hope that there will be something for everyone who reads this paper, however. I would like to think the discussion of the broader societal and philosophical questions that the phenomenon of mental illness raises, contained in Part I, will be of interest to all parties. If not, you have my permission to skip it. 


\section{PART I}

Schizophrenia is a disease that manifests itself in the victim's behavior. The only means we have to know of another person's thoughts and feelings are by way of language and observation of behavior. Behavior and language (which is really a part of behavior) are the only evidence any of us have that anyone else has a "mind" or a "self" in the same sense that each of us believes we possess one of our own. We all tend to feel responsible for our own actions and our own behavior, so it's very difficult to understand how someone else could not be. Yet, all of us at some time or other have experienced some form of intoxication and we can all attest to how it can make us feel and behave abnormally. Intoxication, furthermore, is obviously a physical phenomenon with behavioral consequences.

It may also be useful to recall the dreamstate. When we're dreaming, we often have the sense of being ourselves but perhaps with a different appearance or name or set of memories. I have regular dreams in which I am Captain Kirk of the starship, Enterprise. Can I say that under these circumstances, I am the same person? This may help us to understand what happens in the mind of the schizophrenic patient.

There are obvious precedents for the impact of physiology and physical phenomena on human behavior and personality and thus whatever it is we are referring to when we say, "mind". Furthermore, neither is what we call the "self" inviolable. When I refer to the "self", I think we all conjure up roughly the same associations. "Self" is a certain continuity wa feel from one moment to the next, or a reference point for a set of experiences that cannot be shared identically with anyone else. That reference point, however, is always changing with the accumulation of new experiences and feelings affecting our points-of-view. Can we really say that from one moment to the next with that point-of-view ever changing, however subtly, that we are the same people? Is the self that exists in one fraction of an instant really any less distinct from the self in the next fraction of an instant than from the person next to you?

I think that all this is important to think about not because any of these questions are answerable, but because they undermine many conventions in the way we think about the 
human mind. Those conventions allow us to think in a kind of shorthand which allows us to cope with reality on a day to day basis but may actually impede us from looking at schizophrenia from all the angles. In the same sense, we may all concur that the world is round (a notable exception being the Flat Earth Society), but in our own neighborhoods, up is still up and down is still down - we deal with the Earth on a day to day basis as if it was flat.

I believe we are all inclined to start with a set of preconceptions which tend to prevent a complete exploration of the phenomenon of schizophrenia.

Let us consider several questions with the intention of proposing an alternative view of individuality with regard to mental illness:

(1) What is the motivating force of human behavior, or how can it best be explained?

(2) What constitutes the "self"?

(3) When is a person "responsible" or "not responsible"?

I would like the reader, notwithstanding his or her religious beliefs, to assume for the duration of this paper that all human behavior is a product of the neurochemical and neurobiological and physiological interactions between the human brain and the environment. With approximately a trillion neurons ', the human brain is complex enough to leave plenty of room for all the mysteries and intricacies and spontaneity of human behavior. Some people may consider it depressing to think that there might be nothing more to us than our bodies. My experience, however, is that the more I understand about the functioning of the human body, the more awestruck I am with its complexity. If it's mystery that we need to surround ourselves with, then that complexity should provide us with enough mystery to satisfy us for millenia to come.

The "self" is a unit of identification, concerned less with motivation (the "mind") than with subjective experience. What I would like to suggest concerning the "self" is that what we normally consider the unit of the "self" can be further subdivided into units which can function as "selves" in isolation from the rest of the "self". In other words, a person is actually a complex of different personalities drawing on the same set of experiences. Each section of the brain has its own personality which it contributes to the whole, but which also is peculiar to itself. In turn, each neural circuit contributes its personality to that section of the brain and each neuron lends its personality to its neural circuit. Every brain is a community of sorts. 
Research of the different hemispheres of the brain and studies of people who have had their corpus callosi cut (the corpus callosum is the part of the brain which allows communication between the hemispheres of the brain) has shown that sometimes these people exhibit contradictory behavior by the different sides of their bodies controlled by the contralateral sides of their brains. The classic example is of a man who in anger attempted to strike his wife with his right hand only to have it intercepted by his left. Besides this lateralization, the brain is subdivided further into different areas by structure and function (although a structure may not necessarily be devoted to its one own exclusive function - there may be considerable integration) and several of these areas may be responsible for varying kinds of motivation. The amygdala, the caudate nuclei, and the cingulate gyri all play roles in emotional response and they occur on both sides of the brain. Therefore, there are six separate areas of the brain involved in the generation of emotion - maybe more. How separate and distinct they are has not been ascertained for certain. The point is that there are several different sites. The cingulate gyri are further distinguished from the amygdala and caudate nuclei insofar as the former belong to the cerebral cortex whereas the latter are part of the basal nuclei and midbrain. Furthermore, another area of the cerebral cortex, the prefrontal cortex, is credited with initiating complex, premeditated activities. I mention all this to demonstrate that there is no single point of the brain which initiates all activity or which consolidates all experience. There is no subdivision of the brain that we can identify as more "self" than any other.

What we think of as ourselves is the interplay of all these subdivisions of the brain, yet we cannot simply think of the whole brain as comprising a unified "self". If you remove a particular part of the brain, you will lose that part of the person and that part of the "self" and its experience, but there will still be a person there who will continue to perceive a continuity of "self".

Whether the motivating force for human behavior is biochemical or something else makes little difference in my opinion. The important thing is that human behavior is governed by cause and effect relationships. If the self is as tenuous an entity as l've been describing, it further undermines the notions of "responsibility" and "free will". "Responsibility" implies the existence of a "self" and "free will". 
I believe that on a day to day basis, it may make sense to believe in these concepts, but when seeking to understand the plight of the mentally ill, these concepts must be dismissed as illusory. If we look at ourselves and everything around us from the perspective l've been describing, we must dismiss our own senses of "responsibility" and "free will" as unsupportable concepts, yet our relationships with each other and our daily experiences of life are built on these concepts. It would be impossible to live life in daily terms without the concepts of "individuality", "self", "responsibility", or "free will". Therefore, the issue of whether someone is "responsible" or "not responsible" is a matter of judgment or social consensus, just as the label "insane" has always been. Though no one is truly "responsible" for his own behavior in pure terms, there are clearly some people in society who cannot be considered "responsible" for their own actions even in the sense that we allow for the rest of us. There is also, however, a large unavoidable gray area created by this societal judgment that has great potential for abuse. Thomas Szasz warned us that it is possible for the psychiatric community to act as an agent of evaluation and oppression for the rest of society. Szasz and his compatriots, however, argued that there is no such thing as insanity, and that there is only this judgment, as if there were no mentally ill in need of help, whatsoever - that the psychiatric community is merely an alternative police force, preening society of its undesirable elements ${ }^{2}$.

Again, they are right, in the purest sense. No one is any more responsible for his own behavior than anyone else, and no one. objectively speaking, has any greater hold on reality than anyone else (which undermines everything l've been saying if you think about it, since I have been assuming all along that my view of reality is the only correct one). There are obviously people, however, who will not be able to take care of themselves if left to their own devices, or who will cause harm to themselves or others if no attempt is made to help them. Psychiatry and neurology are helping us more and more to understand the biological basis for human behavior and how it can be influenced pharmacologically. They are sciences like any other with equal potentials for use and abuse. 


\section{PART II}

While neuroscience and psychiatric medicine have made great advances in the understanding and treatment of mental illness, a consensus has not yet formed around a single unifying theory about the origins of schizophrenia. The advent of neuroleptic antipsychotic drugs and their dramatic though limited success in the treatment of schizophrenia has helped to establish beyond question that schizophrenia is a disease of definite physiologic origins. What those origins are, however, has remained elusive. There are many fascinating and diverse theories, each accompanied by its own supporting body of evidence which often cannot be replicated by other researchers, to the frustration of all parties concerned.

Over the course of the last century, schizophrenia - formerly known as dementia praecox - has eluded definition. At times it is referred to as "the schizophrenias" because there are several kinds which may not in fact be related. There appear to be three common sets of symptoms. The first are the "positive symptoms", consisting of hallucinations, delusions, agitation and tension, paranoia, disorganized thinking and insomnia ${ }^{3}$. Second are the "negative symptoms", consisting of amotivation, poor social skills, inability to experience pleasure (anhedonia), limited spontaneous conversation (alogia), poverty of speech, reduced expressiveness, and poor grooming or hygiene 4 . The third, less frequently acknowledged set of symptoms is bizarre, repetitive behavior, such as insatiable thirst (polydipsia), hoarding, pacing, etc s.

"The schizophrenias" have been categorized into "paranoid", "hebephrenic", "catatonic", "disorganized", "undifferentiated", and "residual" 6 . They are alternately categorized by the predominance of either "positive" or "negative" symptoms. "Type I" schizophrenia is dominated by positive symptoms, tends to occur later in the patient's life, and usually responds well to neuroleptic treatment '. "Type II" schizophrenia is dominated by negative symptoms, tends to have a somewhat earlier age of onset, and has a worse prognosis ${ }^{\text {. T The }}$ typical age of onset for schizophrenia is between the ages of seventeen and twenty-eight 9 .

There have been numerous studies of the brain in schizophrenia based on post mortem dissection, and electroencephalogram (EEG) 
readings, as well as various newer imaging systems such as CAT scans, computed tomography (CT), positron emission tomography (PET), and magnetic resonance imaging (MRI). Some of what appear to be the more consistent results are: (1) in comparisons of monozygotic twins discordant for schizophrenia, the ventricles of schizophrenic patients - especially the left lateral horn - are enlarged compared to their normal twin, indicating probable tissue loss somewhere in the brain, most likely in the limbic regions or temporal lobes (Fig. 1) 10; (2) hypoactivity of glucose metabolism in the dorsolateralprefrontal cortex "; (3) reduced hippocampal volume compared to control subjects (Fig. 2) 12; (4) increased concentrations of $D_{2}$ receptors in various limbic regions ${ }^{13}$; (5) more recently, disoriented neurons in the hippocampus ${ }^{44}$ and entorhinal cortex ${ }^{15}$; (6) and some less consistent irregularities in the temporal region such as temporal lobe hyper- and hypoactivity, and diminished temporal lobe gray matter, as well as reduced parahippocampal gyrus volume compared to control subjects(Fig. 1) 16.

Also significant is what has not been found - namely, gliosis and other signs of recent tissue damage, even in the case of schizophrenic patients studied shortly after onset of symptoms 17. This strongly suggests that schizophrenia is the result of a complication of normal development brought on by an earlier - perhaps embryologic - insult to the brain ${ }^{18}$.

For the purposes of my exhibit, I did not concern myself with the distinctions between paranoid, hebephrenic, and disorganized schizophrenia, since in all probability and according to the best of anyone's knowledge they are closely related. The main thrust of my exhibit was based on a theory presented by $\mathrm{Dr}$. Daniel R. Weinberger of the National Institute of Mental Health as presented in the article, "Implications of Normal Brain Development for the Pathogenisis of Schizophrenia" as it appeared in the July, 1987 issue of the journal, Archives of General Psychiatry.

It has been clear for some time that there is a relationship between the positive and negative symptoms of schizophrenia, since they always occur together, albeit in varying proportions. What that relationship is, however, has been particularly baffling to researchers, especially since the positive symptoms would suggest limbic hyperactivity and the negative symptoms suggest prefrontal hypoactivity - seemingly contradictory conditions. Accommodating these 


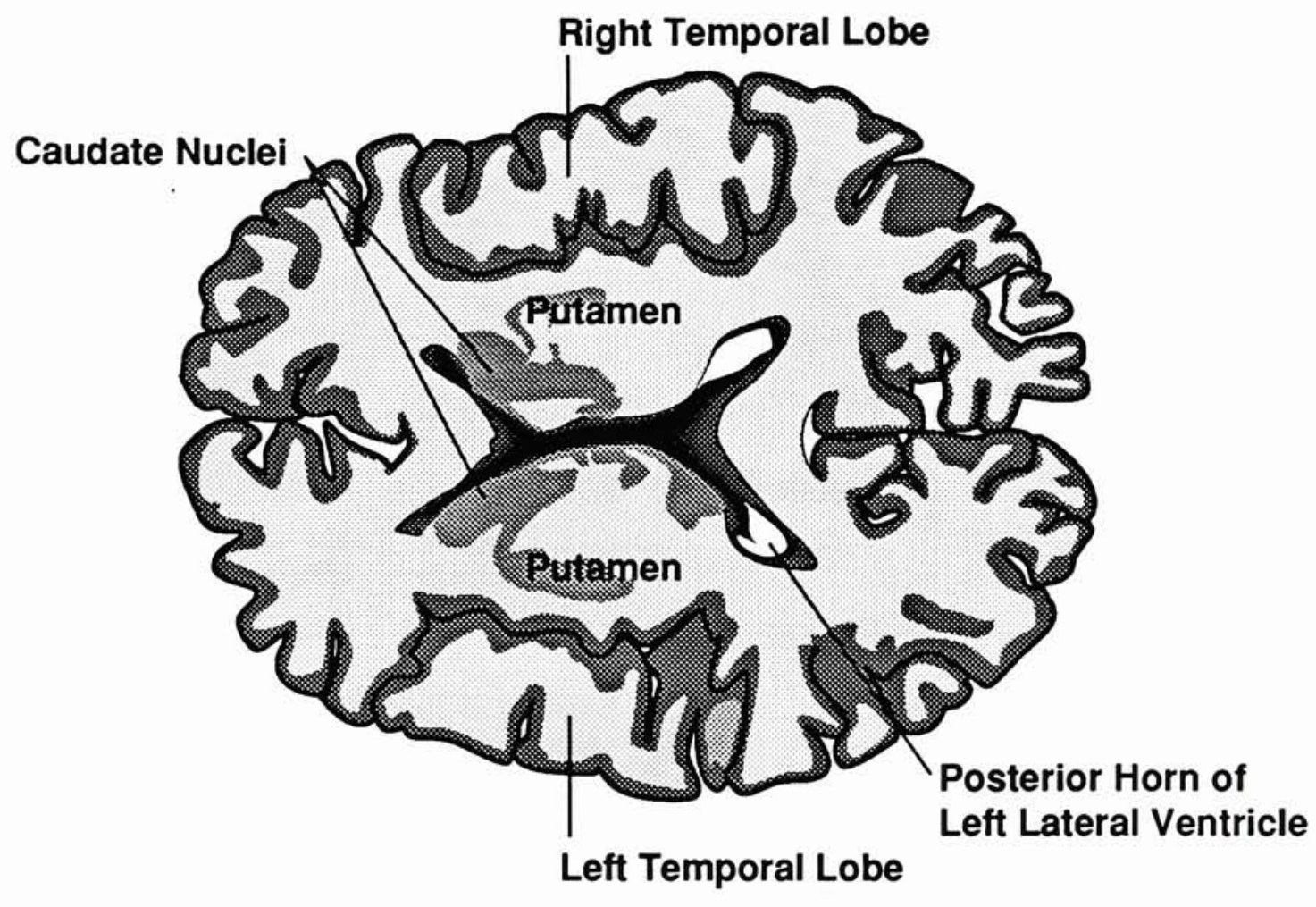

Horizontal Section through Human Brain

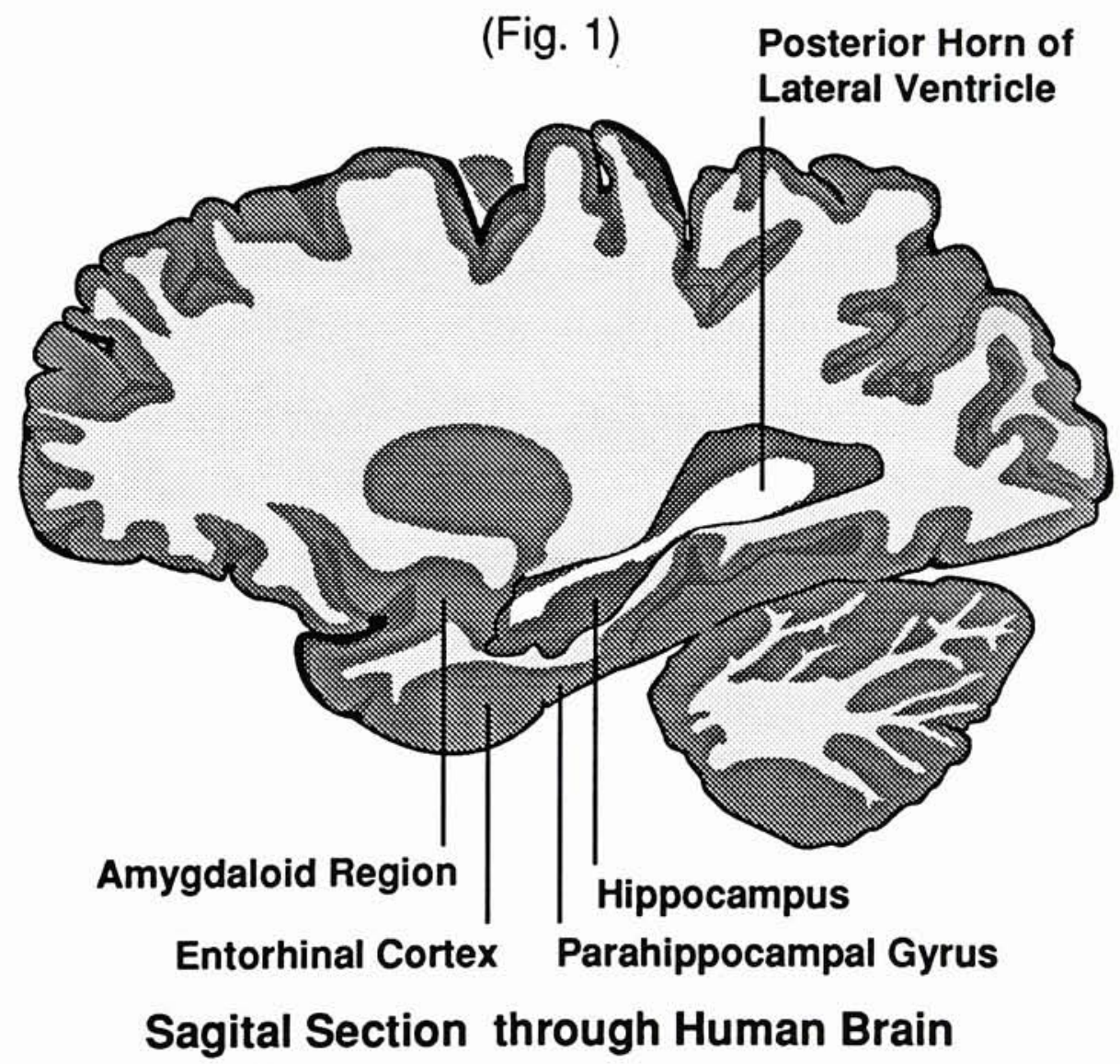

(Fig. 2) 
two apparently disparate sets of symptoms to one another has been one of the greatest challenges for schizophrenia researchers.

Dr. Weinberger made the most coherent attempt to relate the positive and negative symptoms to one another in any theory I had encountered up to the point that I presented my exhibit. Since then, I have encountered other theories presented in other articles which also begin to deal with this problem and are more detailed than Dr. Weinberger's 1987 article. Dr. Weinberger himself was involved in writing a couple of these articles, and so has, in fact, updated his own theory.

The basic premise of Dr. Weinberger's original theory was that some kind of interruption of the A10 dopaminergic neural tract of the brain prevented dopaminergic stimulus of the dorsolateralprefrontal cortex which, in addition to being responsible for schizophrenic negative symptomatology, also resulted in a failure of that region of the brain to inhibit the limbic areas whose hyperactivity is commonly blamed for positive symptomatology 19. The A10 dopaminergic tract has not been mapped in humans, but is believed to run from the ventral tegmental area of the diencephelon to the dorsolateralprefrontal cortex and to branch off to various limbic and midbrain areas along the way. For the purposes of my illustrations, I adapted illustrations of A10 pathways in monkey brains from a study by Dr. Dave L. Felton and John R. Sladek, Jr. ${ }^{20}$

Weinberger and colleagues theorized based on evidence presented by Pycock, et al, that rats with lesions of the prefrontal cortex exhibited limbic hyperactivity ${ }^{21}$ - that a lesion of the portion of the A10 tract that supplies the dorsolateralprefrontal cortex or any other lesion or dysfunction of the dorsolateralprefrontal cortex would cause limbic hyperactivity in humans (Fig. 3) ${ }^{22}$. They theorized that the dorsolateralprefrontal cortex would normally exercise an inhibiting effect either on the limbic areas directly or on the ventral tegmental area which would in turn reduce dopaminergic stimuli to the limbic and midbrain regions (Fig. 4$)^{23}$.

Because the dorsolateralprefrontal cortex is the region of the human brain associated with its highest rational functions, a lesion resulting in its dysfunction would serve to explain schizophrenia's negative symptoms ${ }^{24}$. Meanwhile, hippocampal and thalamic dopaminergic hyperactivity would help to explain the delusions, hallucinations, and occasional sensory overload experienced by 


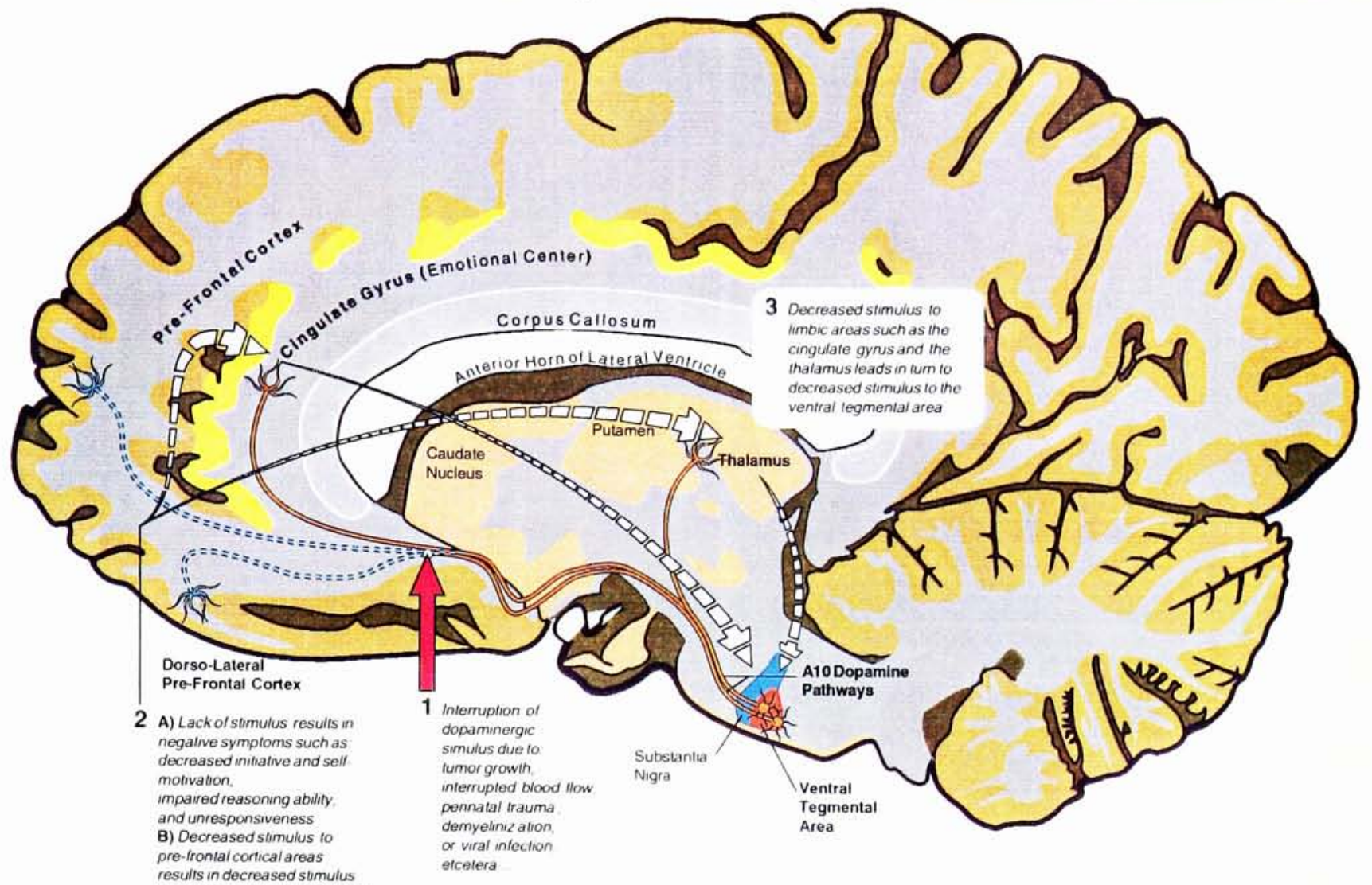

(Fig. 3)

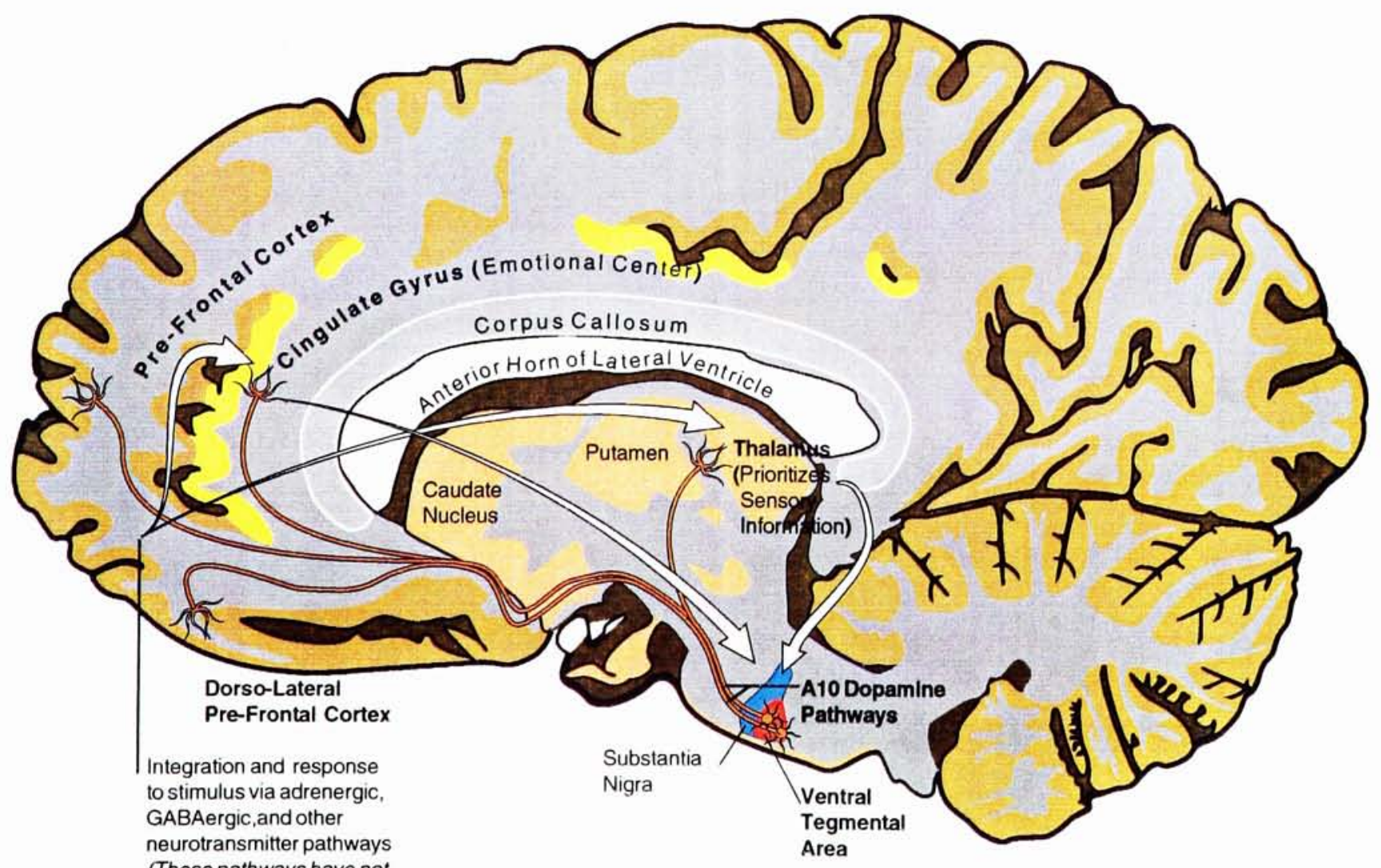

(These pathways have not

been specifically mapped)

(Fig. 4) 


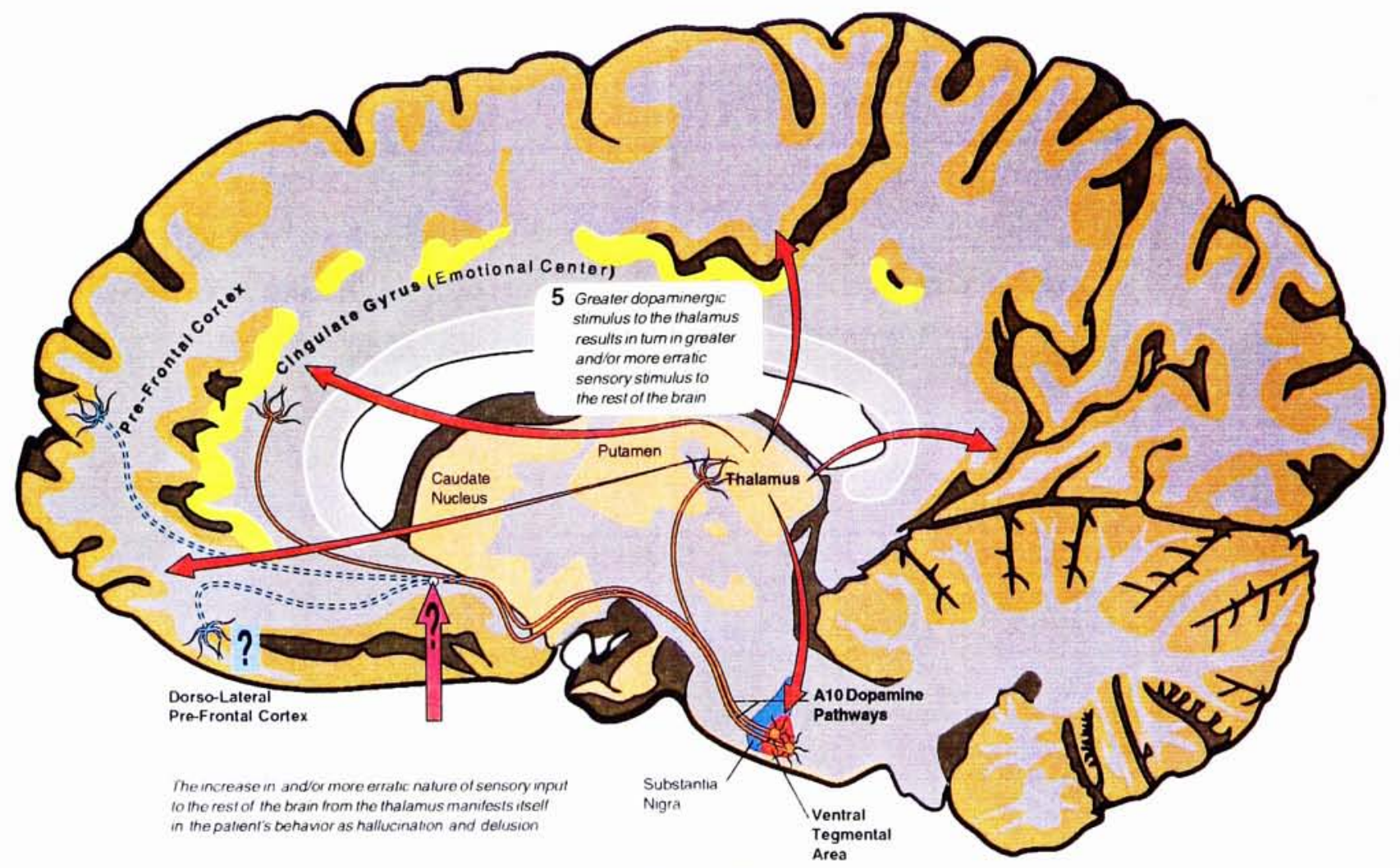

(Fig. 5)

schizophrenics, since those regions - especially

the thalamus - normally regulate sensory stimuli to the brain (Fig. 5) 25 . Dopaminergic hyperactivity of other midbrain and limbic areas such as the amygdala, nucleus accumbens, and especially the cingulate gyrus, could explain the emotional difficulties experienced by schizophrenic patients (Fig. 6) ${ }^{26}$

The nature of the lesion of the A10 tract or dorsolateralprefrontal cortex might ultimately be important to the treatment of the individual patient's condition, but it is not important to our understanding of the basic disorder. The lesion could be caused by something as simple as diminished blood flow to the region in question, a tumor, a genetic imperfection, trauma, or a virus $^{27}$. Alternatively, it could be the result of a change in expression of dopamine receptors on the neurons of the dorsolateralprefrontal cortex resulting in insensitivity of that region to dopaminergic stimulus (Fig. 7) ${ }^{28}$. This change in expression of dopamine receptors could be the product of genetics or an auto-immune reaction to one's own dopamine receptors ${ }^{29}$. The important consequence of all these conditions is that the dopaminergic stimulus to the dorsolateralprefrontal cortex would be obstructed. 


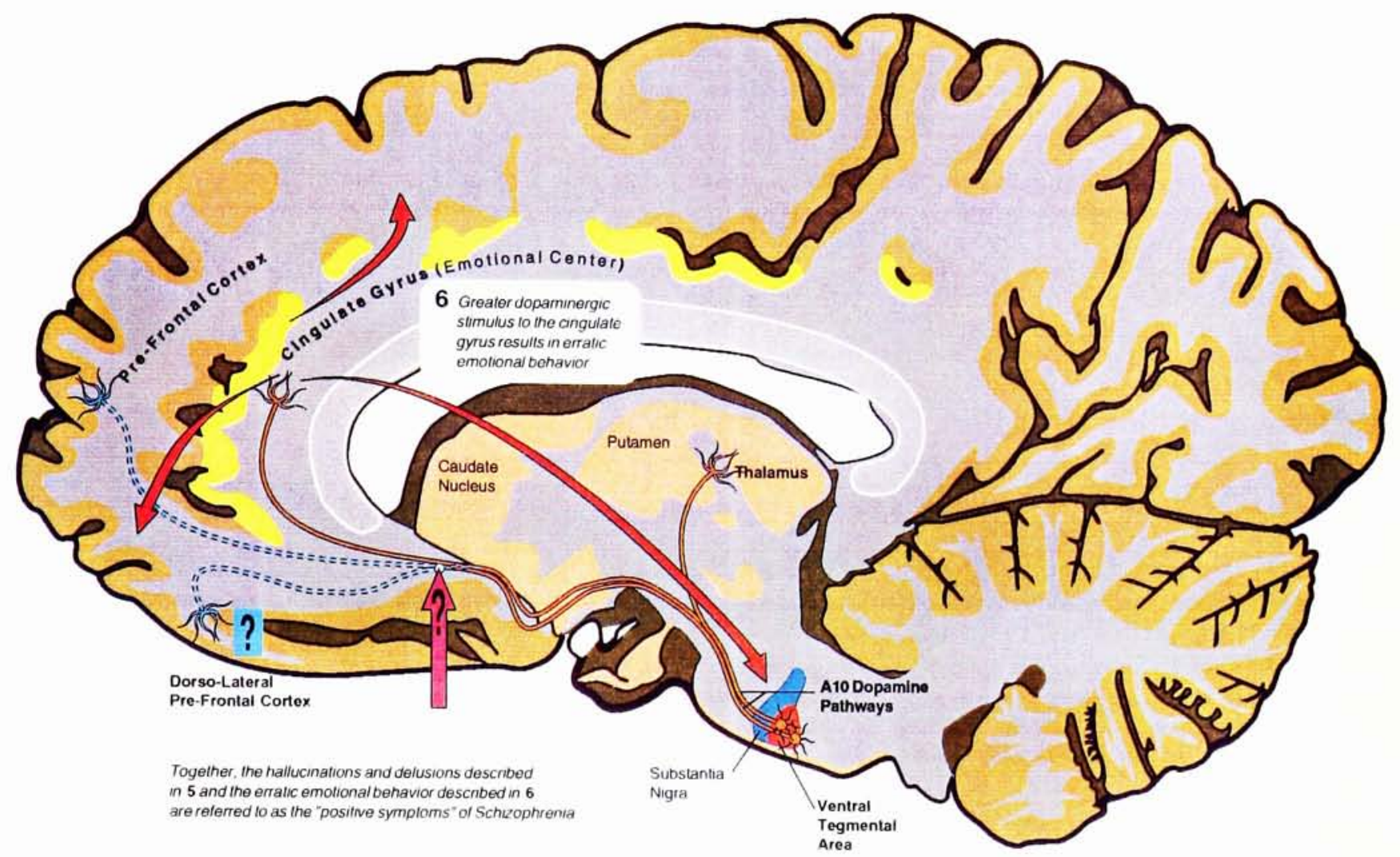

(Fig. 6)

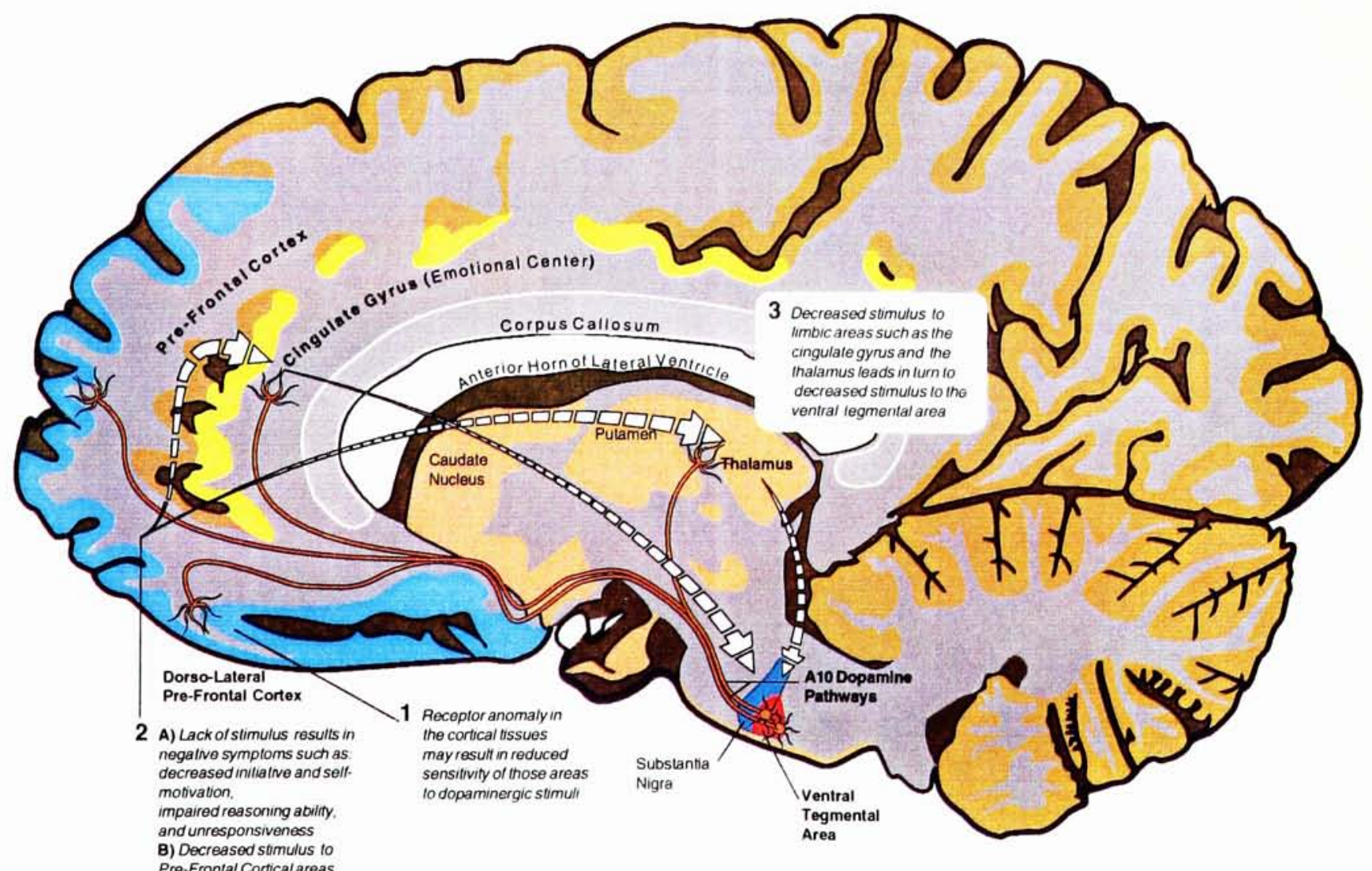

Pre-Frontal Cortical areas

results indecreased stimulus

to dependent areas of the brain

(Fig. 7) 
Neuroleptics function by blocking the dopamine receptors on those regions of the brain associated with the positive symptoms of schizophrenia, such as the thalamus and cingulate gyrus (Fig. 8) ${ }^{30}$. They do not distinguish between these receptors and dopamine receptors on the rest of the brain and so may exacerbate negative symptoms somewhat by blocking these receptors on the dorsolateralprefrontal cortex. They may also cause extra-pyramidal side effects such as tremors in the hands and uncoordination by blocking dopamine receptors on midbrain regions, such as the caudate nucleus, which participate in the coordination of physical activity (Fig. 9) $)^{31}$.

A major obstacle for the medication of any brain disorder is the blood-brain barrier which tightly monitors the chemistry and nutrition of the brain ${ }^{32}$. The endothelial cells forming the capillaries of the rest of the body are much more loosely organized than those of the brain, permitting diffusion of nutrients and waste elements to and from the blood and body tissues. The capillaries of the brain, however, are organized in such a way that nutrients must be actively transported across the endothelial membrane ${ }^{33}$. Thus is the delicate chemistry of

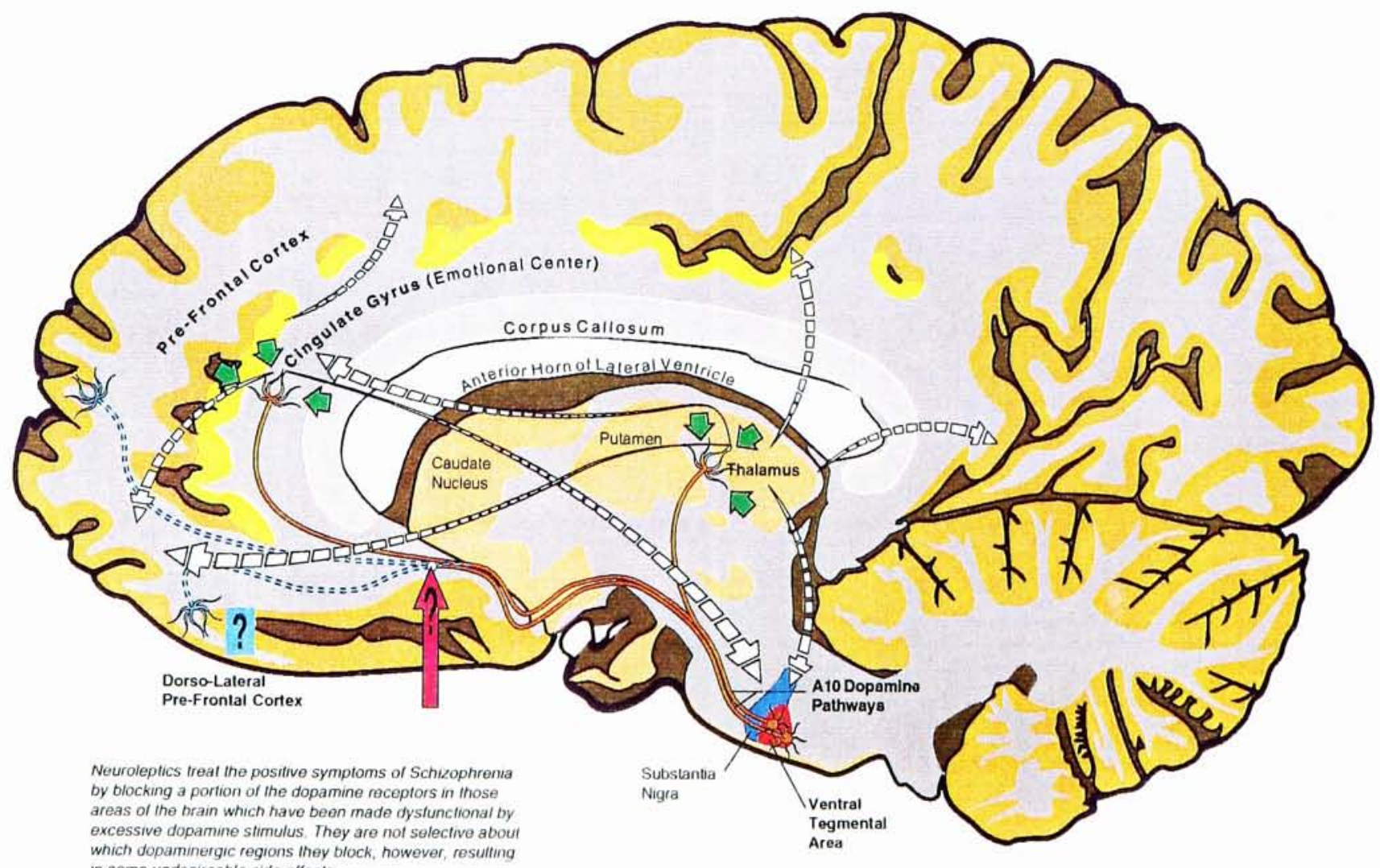

(Fig. 8) 


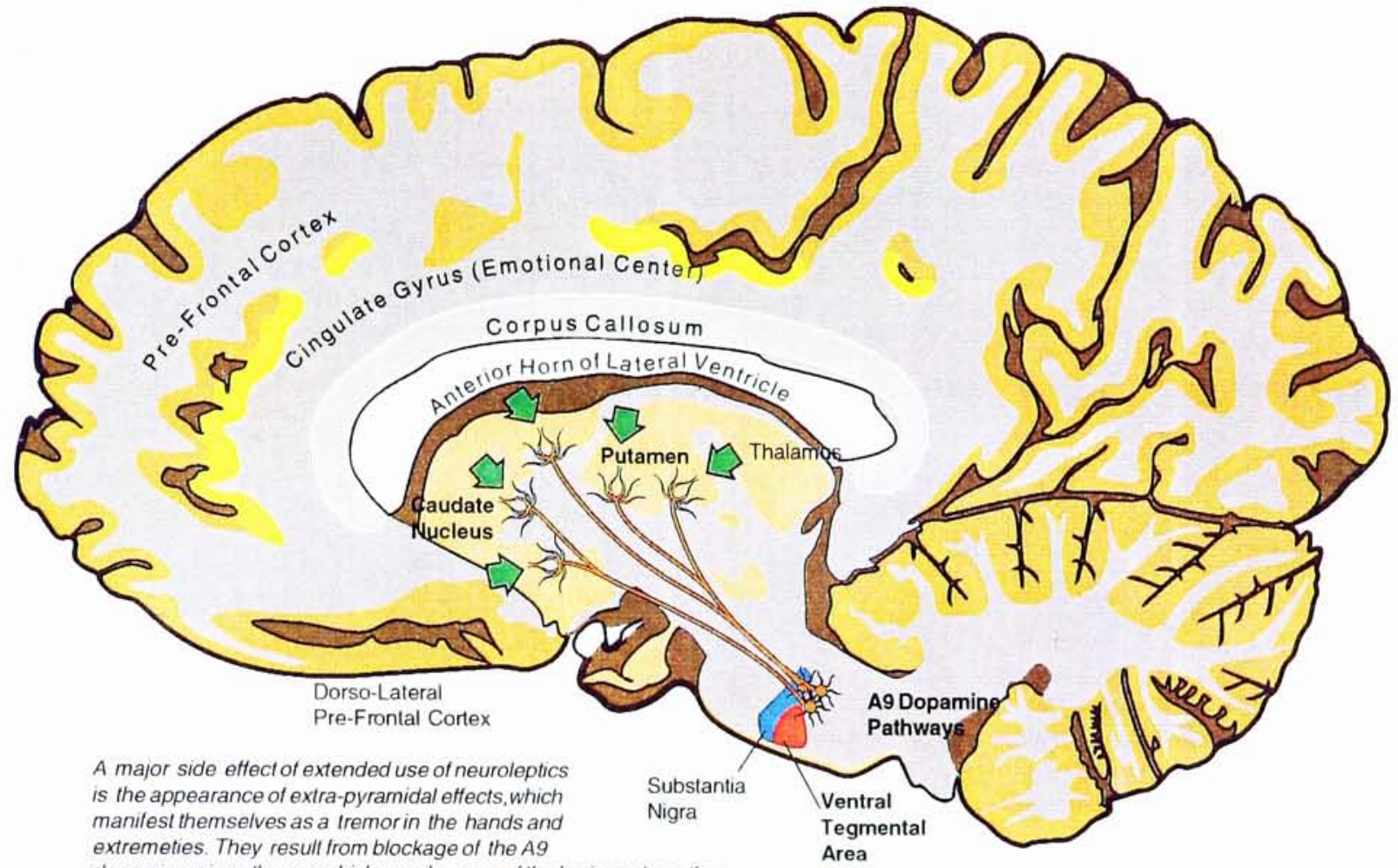
extremeties. They resull from blockage of the A9

dopaminergic pathways which supply areas of the brain such as the

caudate nucleus and the putamen which, in tum, help in the coordination of movement. All neuroleptics cause

extra-pyramidal effects with the notable exception of clozapine which selectively blocks only the A10 dopaminergic pathways of the brain. It has not yet been determined why clozapine, in contrast to other drugs, selectively targets the A10 pathways.

(Fig. 9)

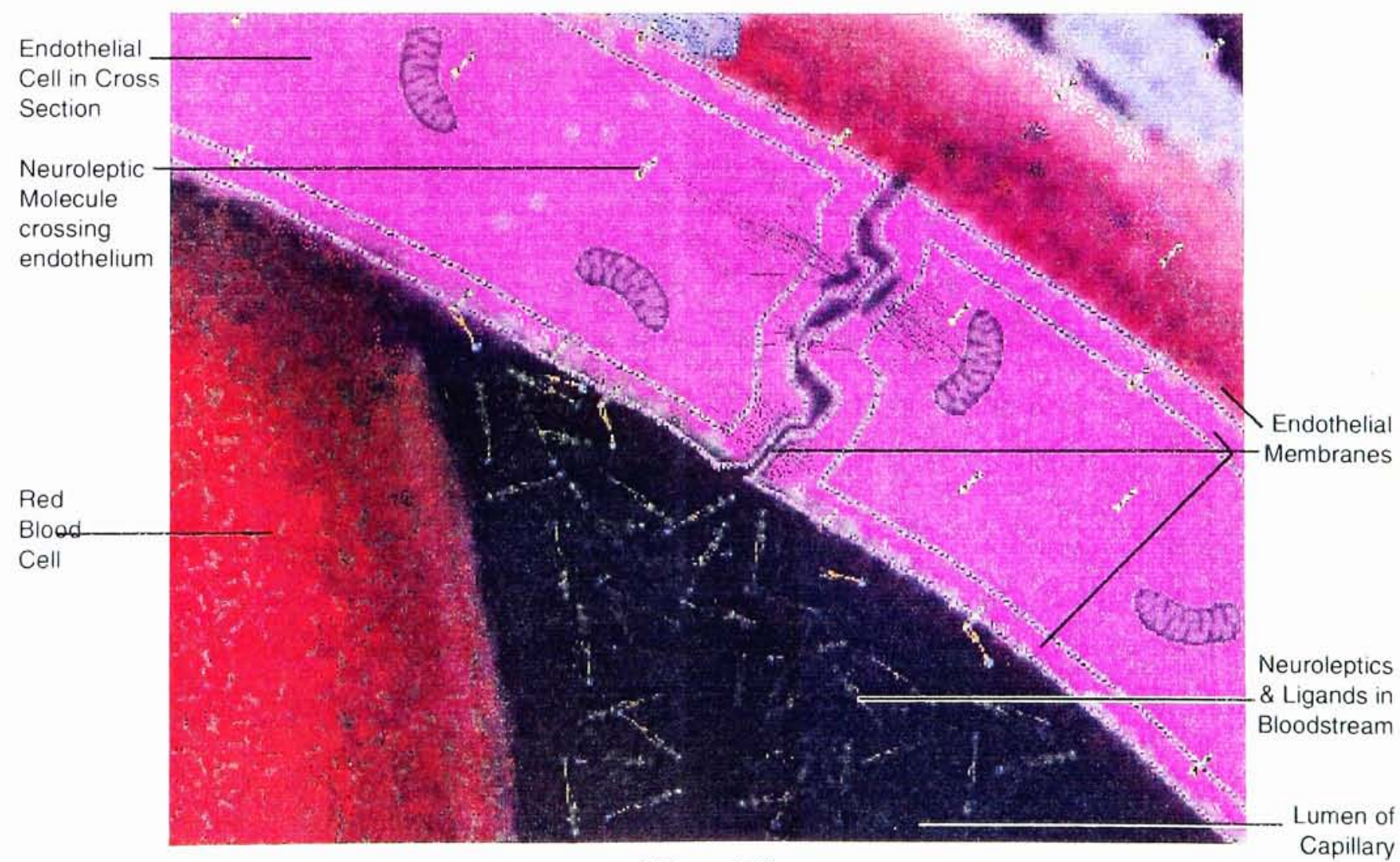

(Fig. 10) 
the brain carefully controlled. Because of this, brain medications are severely limited by their ability to cross this barrier. Generally, neuroleptics and other lipid-soluble drugs cross this barrier relatively easily (Fig. 10), whereas water-soluble drugs have to be carefully designed to fool this natural monitoring system

Abnormalities in expression of dopamine receptors are also significant and may occur in several basic ways. I have seen no way in which all of schizophrenic phenomena may be explained in terms of receptor anomalies. It is possible, however, that receptor anomalies play a major role in the manifestation of the disease.

Dopamine receptors occur in basically two types, referred to as $D$, and $D_{2}$ receptors ${ }^{35}$. Generally, it is known that D, stimulates cyclic adenosine monophosphate (AMP) activity and therefore probably increases cell metabolism or some aspect of it, whereas D inhibits cyclic AMP activity and consequently is most likely to inhibit cell metabolism, regulating the activity of $D,{ }^{36}$. It is known that all effective antipsychotic drugs bind strongly to $D_{\text {; }}$ (Fig. 11) demonstrating that it is by the inhibition of this receptor activity that neuroleptics exercise their effect.

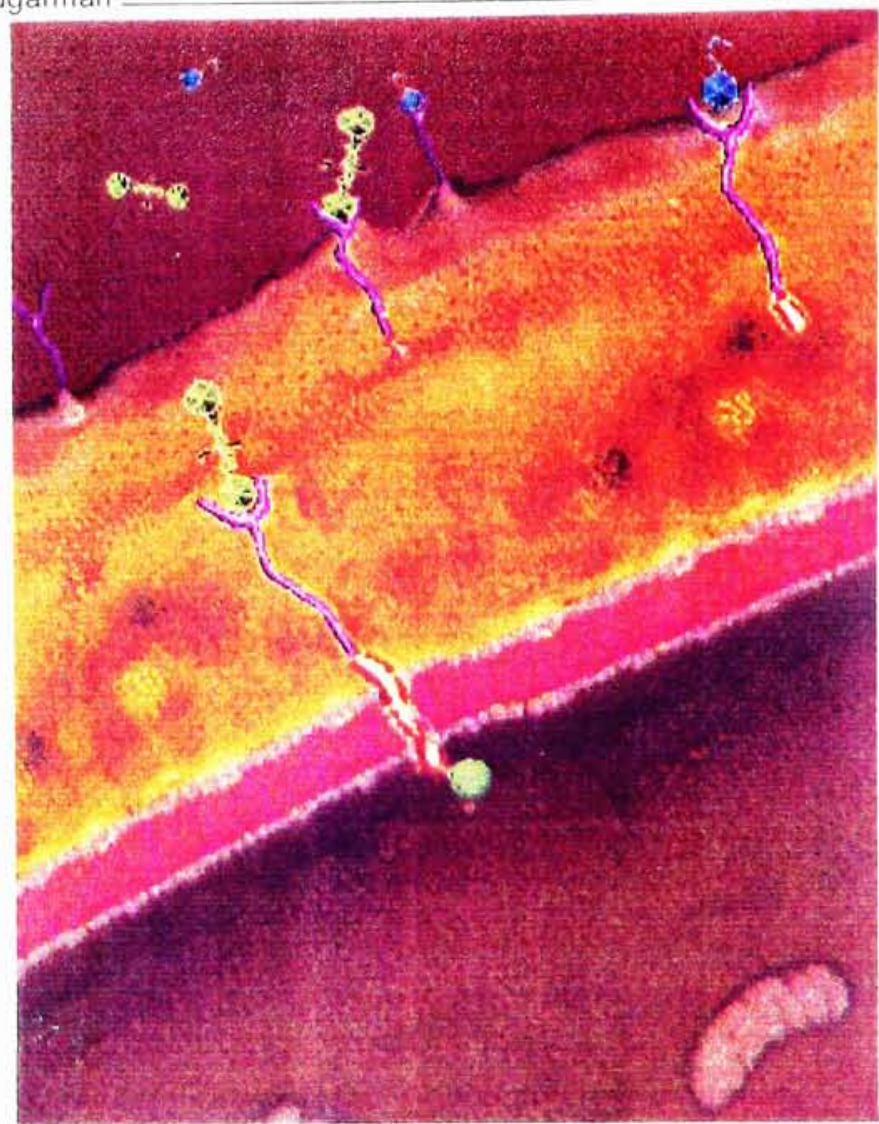

(Fig. 11)

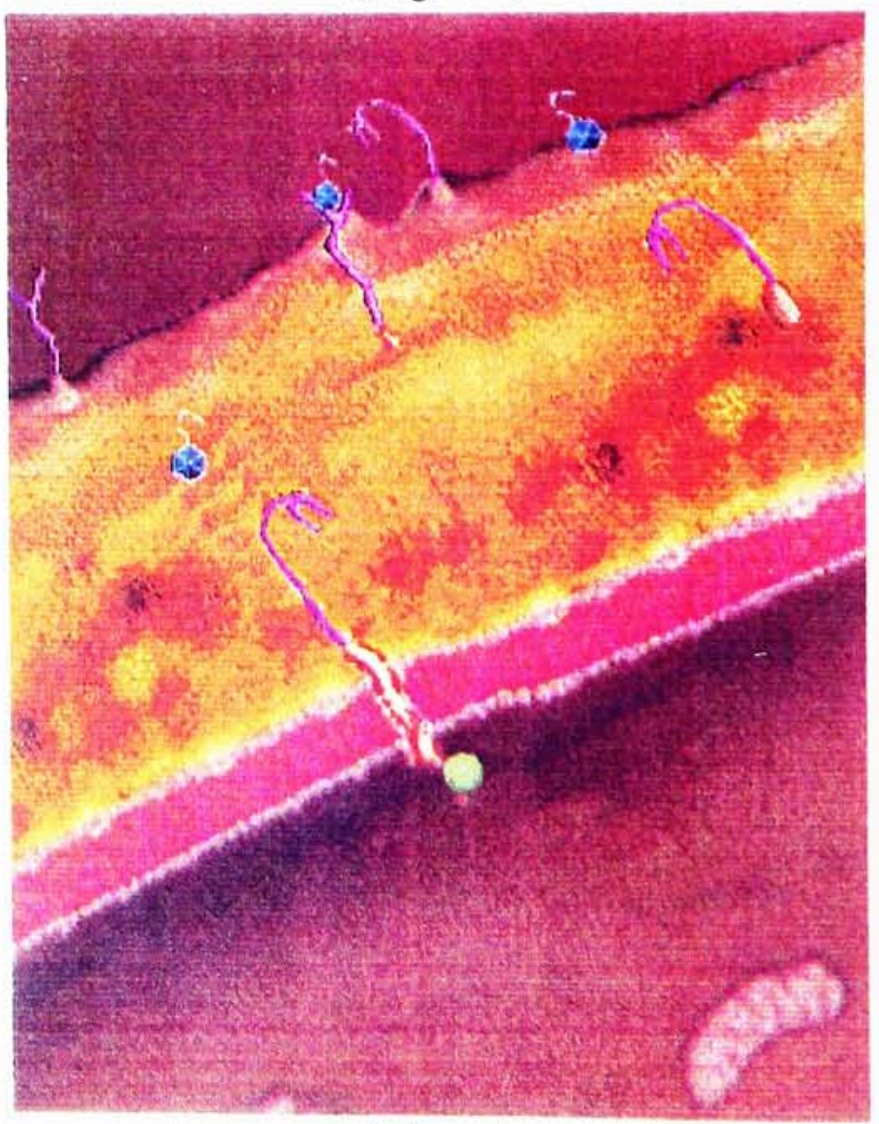

(Fig. 12) 
A receptor anomaly may conceivably be a genetically expressed defect (Fig. 12) whereby one or both of the two kinds of receptors fails to function properly (is underactive or overactive). This hypothesis would fail to explain the typically late onset of the disease, however, unless it was only the neurons of the dorsolateralprefrontal cortex or related neurons which tended to express these hypothetically defective receptors.

Alternatively, it is possible that the body may acquire an immunity to its own dopamine receptors (one kind or both) and may express antibodies which may attack and impair the

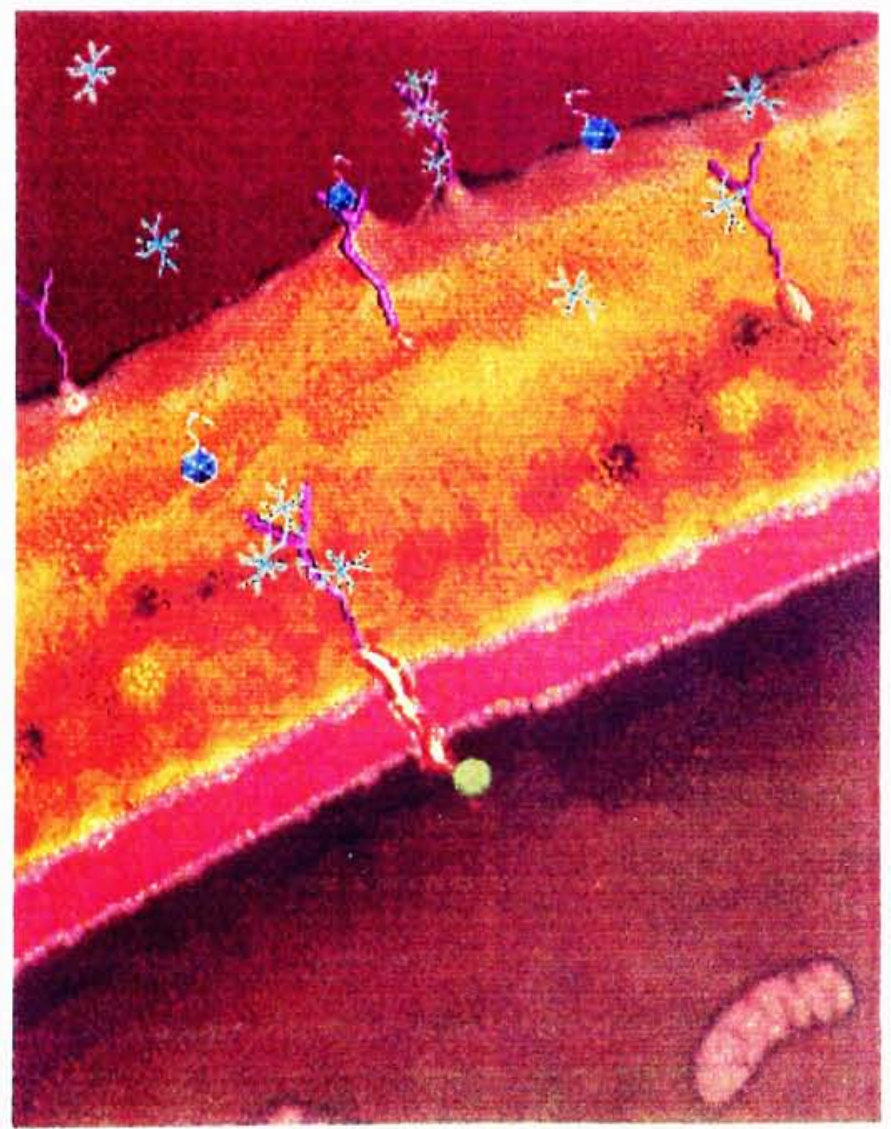

(Fig. 13) functioning of these receptors (Fig. 13) ${ }^{38}$. This is very similar to what happens in the disease, myasthemia gravis. The body acquires an immunity to the receptors expressed on the body's muscle tissue cells which receive efferent stimulus. Antibodies destroy these receptors, preventing the interaction of otherwise healthy muscle and nerve tissue. The victim can no longer stimulate the affected muscle tissue and so can no longer move his own body. Unstimulated muscle tissue atrophies and the victim eventually dies when the receptors that receive stimulus on such major muscular organs as the heart, lungs, and gastrointestinal tract are destroyed ${ }^{3 *}$. The shortcoming of this theory as applied to schizophrenia is that such a scenario would seem to affect all areas of the brain more or less equally whereas schizophrenia appears to affect different areas of the brain in different ways.

A third receptor anomaly model is advanced by Dr. Philip Seeman of the University of Toronto and his associates in the article, "Dopamine receptors and transporters in Parkinson's disease and schizophrenia", which appeared in the July 1990 issue of The FASEB Journal. I cannot pretend to fully understand this model. It involves more chemistry than I can really follow 
at this point. Basically, there is a fault (acquired by unspecified means - probably genetically) in the relationship of the two receptors as embodied by a protein called a "second messenger" ${ }^{40}$. Second messenger proteins are not exclusive to dopamine receptors. They are the means by which all receptors manipulate the metabolism of the cell. The receptor reacts to some external agent (e.g.; dopamine) which, in turn, brings about a reaction with its second messenger which, in its turn, reacts with the cell's metabolism "'. More recently, moreover, Dr. Seeman, et al, have demonstrated that clozapine - a new and unusually effective neuroleptic agent which appears to affect the negative symptoms of schizophrenia in contrast to other neuroleptics - binds this second messenger protein ${ }^{42}$. I do not understand how this may affect schizophrenia, however.

More recently, schizophrenia research has favored studies of hippocampal anomalies. Several studies have demonstrated reduced hippocampal volume among schizophrenic patients as well as eccentric alignments of hippocampal neurons ${ }^{43}$. Normally pyramidal neurons of the hippocampus and entorhinal cortex are aligned perpendicularly to the surface membrane or pia mater of the brain ${ }^{44}$. Recent studies have discovered, however, that groups of these neurons are misaligned in a random fashion at angles of from fifteen to ninety degrees causing them to synapse with neurons with which they ordinarily would not ${ }^{45}$. The issue, furthermore, isn't whether or not this disorientation occurs, but rather, how much, since the same phenomenon was found to exist consistently in the control subjects to a much lesser degree ${ }^{46}$.

An involvement for the hippocampus would help to explain some of the more troublesome schizophrenic phenomena. It has been found, for instance, that hippocampally lesioned rats exhibit bizarre, repetitive behaviors during periods of stress - such as feeding time - similar to those exhibited by many schizophrenic patients ${ }^{47}$.

The hippocampus also functions extensively in memory recall in conjunction with the temporal lobe (especially Wernicke's area) and the parahippocampus ${ }^{48}$, both of which have been shown in studies to exhibit reduced volume and abnormal metabolism of one kind or another in schizophrenic patients ${ }^{49}$. It has been suggested that perhaps the voices which schizophrenic patients hear in their heads may be memories triggered by abnormal hippocampal activity ${ }^{50}$. A 


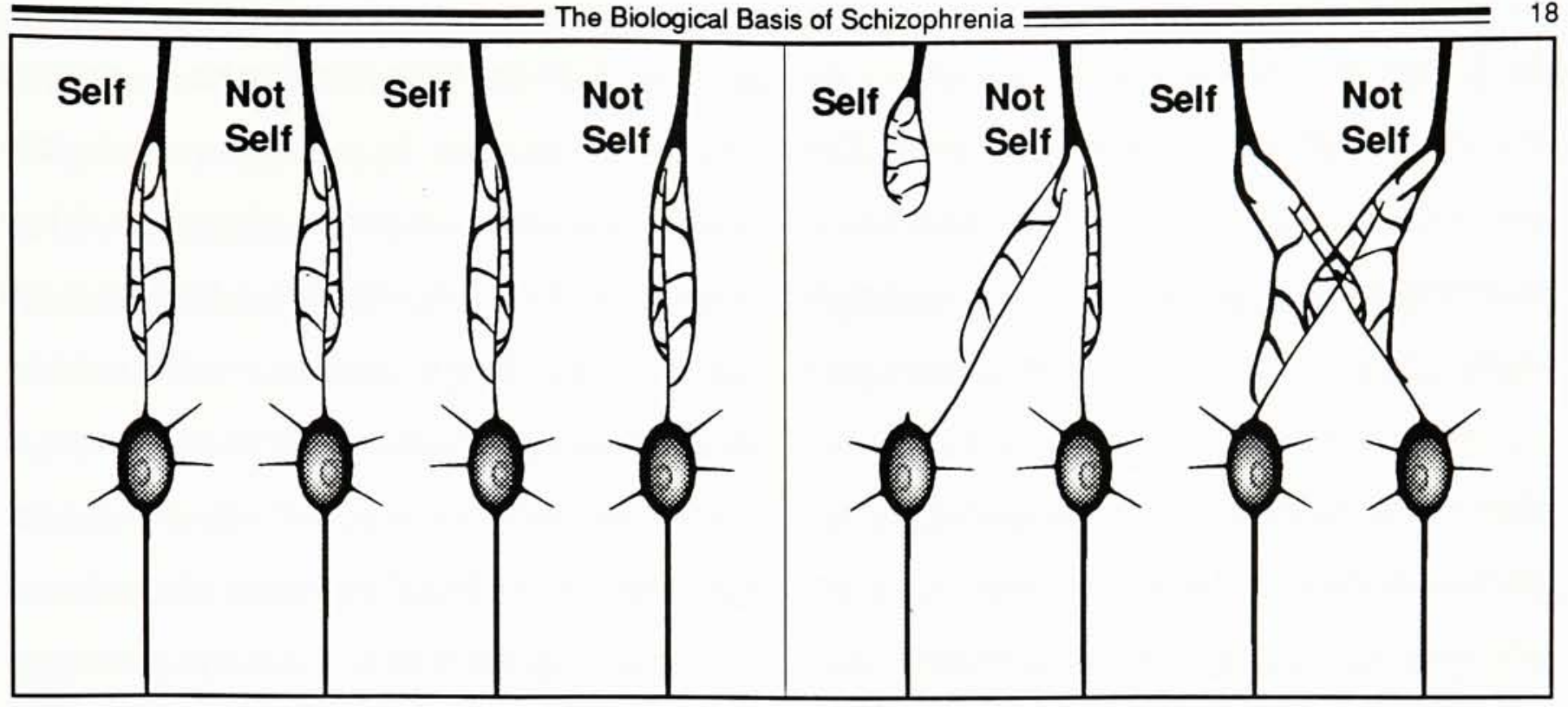

(Fig. 14)

more elaborate hypothesis is that, instead of experiencing his own internal voice as his own, a schizophrenic patient's internal monologue may be misdirected through channels that the brain normally reserves for "not self" and so it is experienced as someone else's voice inside his head. Probably this process would somehow involve memory, since we immediately replay our ownthoughts several times as we think ${ }^{51}$. The difference between remembering something as one's own words or someone else's may be as little as the difference between one synapse and another (Fig. 14). If those synapses occur in the hippocampus and the neurons are misaligned as has been demonstrated, then this may be exactly what happens (although it is most likely a good deal more complex).

This evidence and theory do not necessarily conflict with Dr. Weinberger's theory, but rather elaborate on it. The A10 pathway very likely either passes through or is mediated by the hippocampus and the entorhinal cortex.

I recently spoke to a psychologist named, Michael Miran, who with his wife, Esta Miran, is proposing a model of the schizophrenic brain which is called "homeostatic". The emphasis of the model is the interrelationship of the parts to create a whole. I have only recently encountered this model and have not studied it sufficiently to write about it with confidence. One thing that Dr. Miran related to me particularly caught my interest, however. He said that normally, if you walk into a situation that at first inspection causes alarm, but upon closer inspection is something that you can identify as nonthreatening, that second inspection is your 
dorsolateralprefrontal cortex exercising an inhibition reaction on your limbic system. The example he used was that if you walk into a room with a stuffed lion in it and don't immediately identify that it is stuffed, you will react with alarm - your hair will rise, your pulse will rise, etc. When you realize that it is stuffed, your dorsolateralprefrontal cortex exercises an inhibiting action on your limbic system to calm you down, manifested internally as you tell yourself, "Oh - it's all right - it's just a stuffed lion." According to Dr. Miran, what happens to the schizophrenic patient is that dopaminergic and adrenergic tracts to the dorsolateralprefrontal cortex become overstimulated and the dorsolateralprefrontal cortex kind of "locks up". Thus, it fails to exercise its inhibiting effect on the limbic system. Furthermore, this "lock up" is a kind of overstimulation which "overflows" to nearby areas of the brain, stimulating the temporal lobe and activating memories stored there. Consequently, when confronted with the stuffed lion, the response of the schizophrenic patient is not mediated by the dorsolateralprefrontal cortex, resulting in continued alarm with accompanying confusion, halluciations and delusion.
Drs. Esta and Michael Miran have used this model as the basis for a program of therapy which has shown a high rate of success. A key element of their program is that they treat the patient as brain-injured, rather than psychologically disturbed. While not aimed at curing the schizophrenic patient, the Inside/ Outside Program has shown great effectiveness in reeducating schizophrenic patients permitting them to better cope with the outside world ${ }^{52}$.

At this point, I have constructed my own model of schizophrenia, based on all the different theories and studies I've sampled. First of all, an embryologic malformation occurs in the hippocampus and/or entorhinal cortex, perhaps due to genetic defect, anoxia (prenatal oxygen deprivation) or maybe due to a viral infection contracted during the second trimester of pregnancy s3. The condition manifests itself later on in adulthood only as normal development brings the dorsolateralprefrontal cortex to maturity ${ }^{54}$. It is the strain of having this last area in operation, perhaps along with unusual stress (onset of schizophrenia is frequently associated with periods of high stress ${ }^{55}$ ), which overloads the malformed areas ${ }^{56}$. Failure of the hippocampus, etc., to regulate stimulus to the dorsolateralprefrontal cortex causes the 
dysfunction of that area and consequently negative symptomology. It is likely that there is a GABAergic tract which normally runs back to the hippocampus from the dorsolateralprefrontal cortex and acts to inhibit dopaminergic stimulus to the limbic system and midbrain from the hippocampus. It has been demostrated that schizophrenic patients exhibit reduced GABA (gamma-amino-butyric acid - a major neurotransmitter in the brain which functions mainly as an inhibitor of dopamine tracts, but is likely to have other functions as well ${ }^{57}$ ) levels in the hippocampus which has been in turn associated with higher dopamine levels in the amygdala ${ }^{58}$. Dysfunction of the dorsolateralprefrontal cortex, in turn, causes dysfunction of this GABAergic tract. Limbic function is nomally regulated by hippocampal dopaminergic stimulus. That stimulus is, in turn, regulated in part by this inhibitory GABAergic stimulus from the dorsolateralprefrontal cortex. Dopaminergic overstimulus of limbic and midbrain regions accounts for emotional instability, agitation, and other positive symptoms, while hippocampal dysfunction and overstimulation causes activation of memories and perception of voices as discussed on page seventeen ${ }^{50}$.

\section{PART III}

Illustration of my thesis broke into four parts.

The central illustration was a series of Adobe Illustrator 3.0 images (Figs. 1-9) describing Dr. Weinberger's theory as described in his article which appeared in the July 1987 issue of Archives of General Psychiatry as mentioned earlier. These were created by scanning a photo of a brain sagital section from pgs. 43,69 and 79, of Atlas of the Human Brain in Section, by Melville Roberts, B.S., M.D., and Joseph Hanaway, A.B., M.D ${ }^{60}$. Using it as a template, I traced it manually and added graphics.
As a reference for the $\mathrm{A} 10$ dopaminergic pathways, I used illustrations from a publication by Dr. Dave Felton and John R. Sladek, Jr. of pathways reported to exist in monkeys ${ }^{61}$. I took considerable liberties in extrapolating what paths these projections might take in the human brain. I did, however, consult with Dr. Lamberti of Strong Memorial Hospital as to the probable accuracy of my illustrations.

As a tangent to Dr. Weinberger's theory, I went into further detail in my description of the means by which a receptor anomaly might 


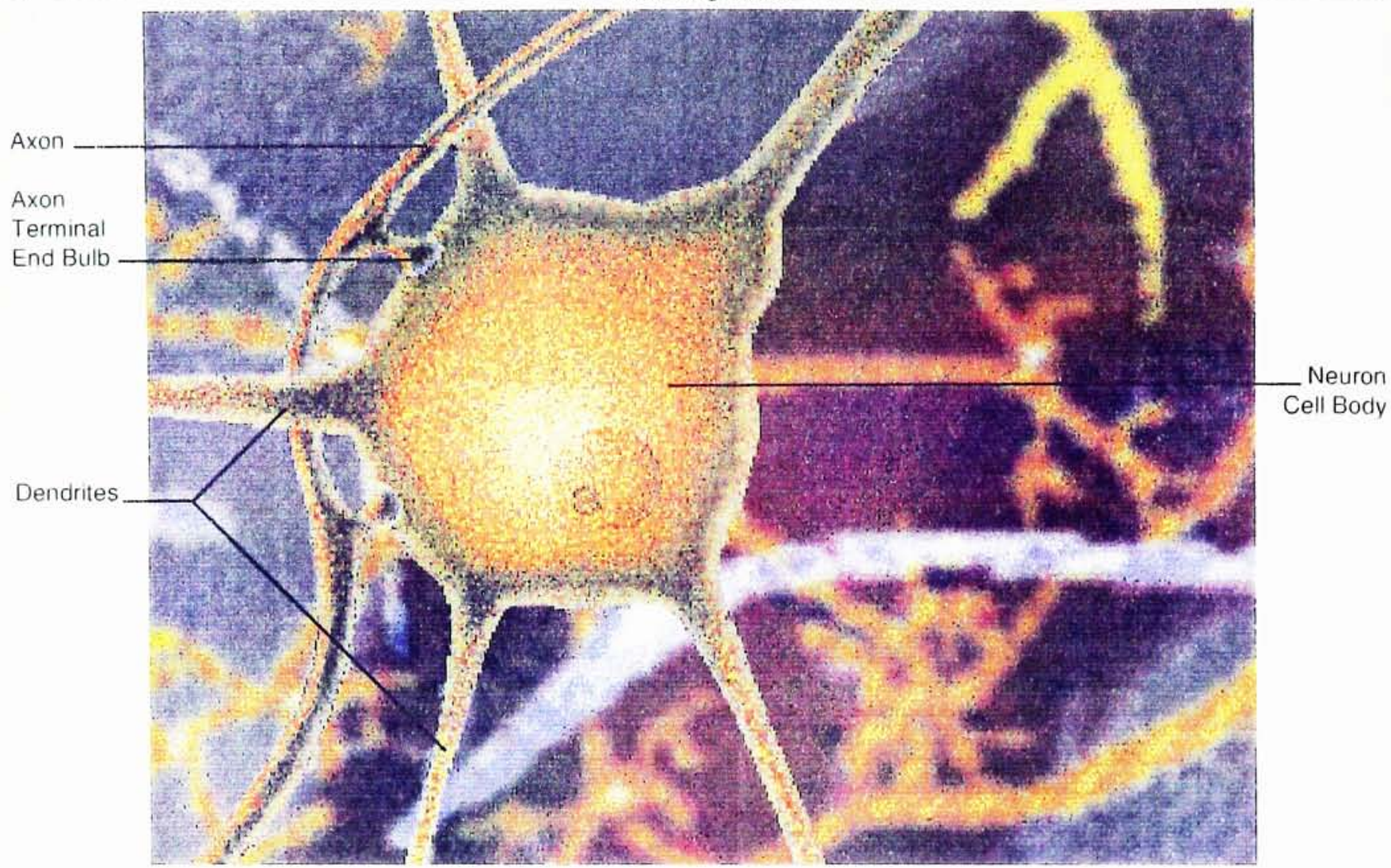

(Fig. 15)

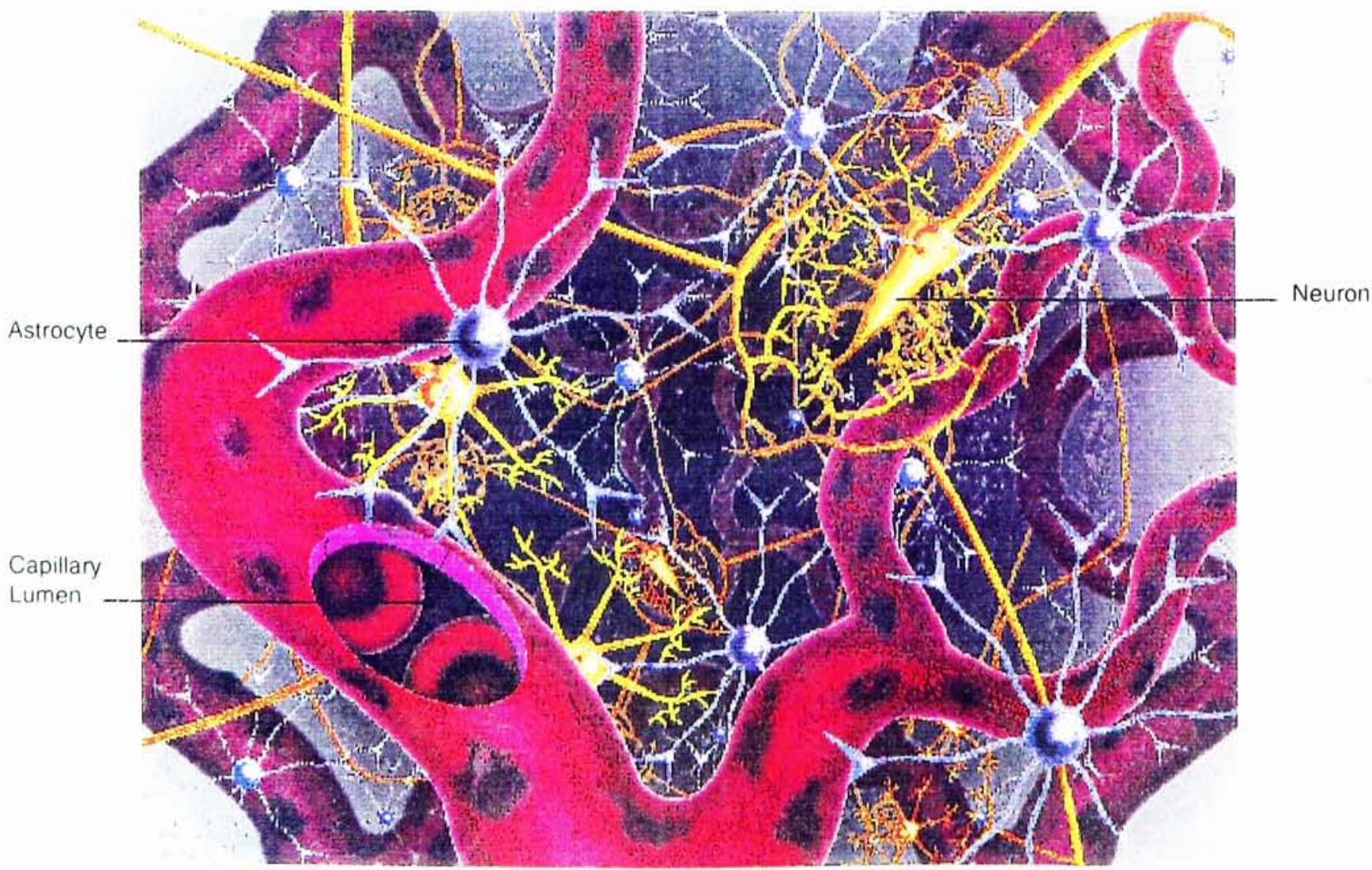

(Fig. 16) 


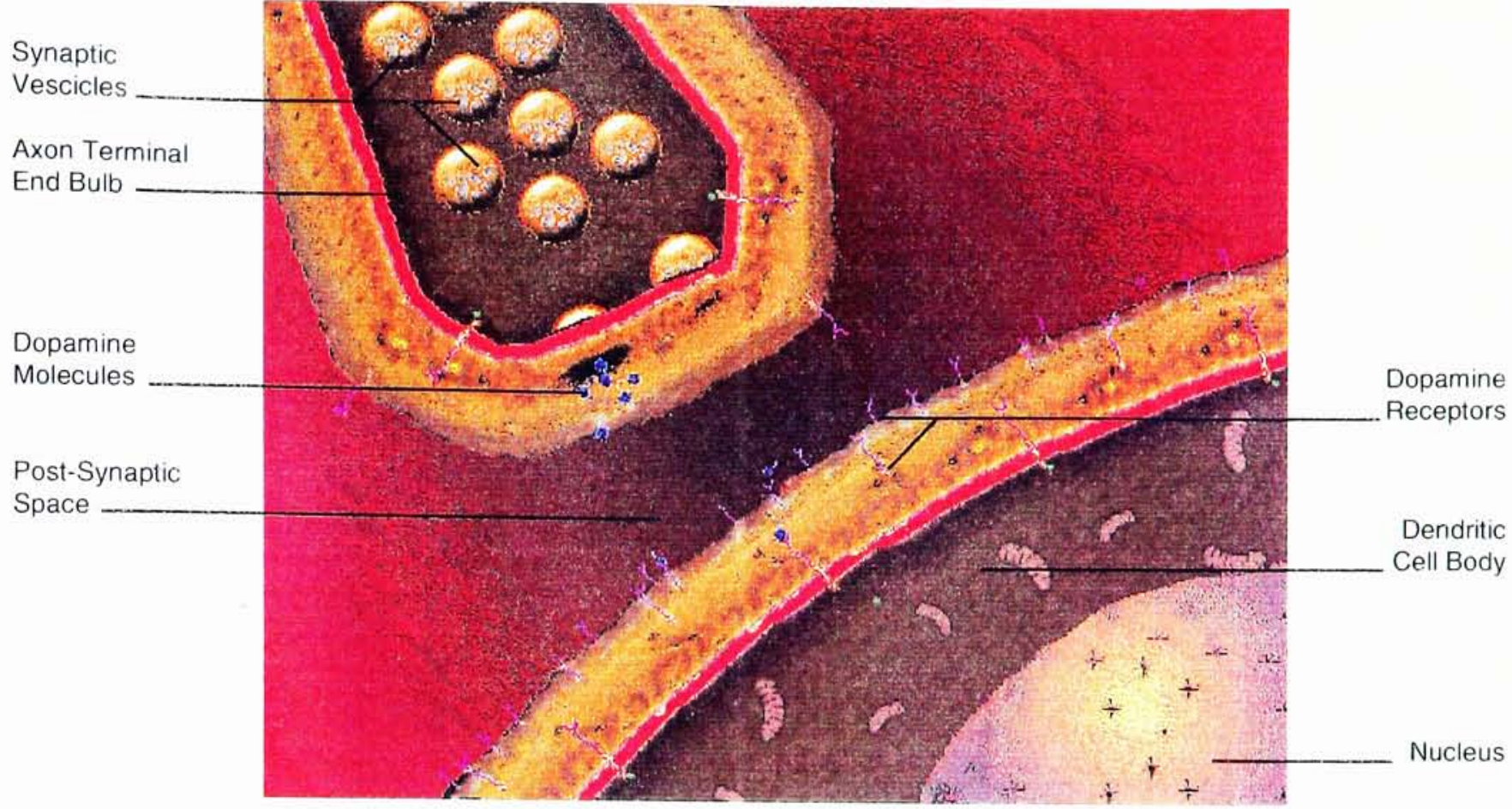

(Fig. 17)

printer.

The fourth section of my exhibit was an animated piece generated in Macromind Director 2.0. It was derived from my original set of Adobe Illustrator 3.0 pieces and did not differ from it significantly in content. The only difference was that it more explicitly demonstrated the time element with animation. The imagery lost some of the clarity of the original Adobe Illustrator 3.0 pieces because it was necessary to translate them into a pixilated PICT image format in order to get them into Macromind Director 2.0.

I chose to stick entirely to the computer as my medium because, in the first place, I believe that it was in my own best interest to develop these skills, as they are likely to be most in demand in the future. Secondly, the computer allowed me to execute what looked like final pieces to show the people I was consulting with, and yet allowed me to change a great deal if I needed to without ruining the piece. Also, I was able to save my steps along the way if I needed to back up to an earlier stage of the illustration. In the third place, it allowed me to repeat an image several times for several different illustrations or within the same illustration without having to redraw it over and over again.

I particularly enjoyed using the Adobe Photoshop 1.0 airbrush function which allowed me to get effects similar to what might be expected with an airbrush, but with much more 
occur. In contrast to the previous set of neuroanatomical schematic images this set of images was meant to describe the possible pathogenesis of schizophrenia at a cellular level in a more realistic manner. I took this approach because it seemed to me that, most illustration of celllular neurological activity has been executed in a highly abstract and schematic manner. A more realistic, colorful, three-dimensional set of illustrations of the neural cell environment might bring more interest, excitement, and understanding to the field. To achieve this, I used a combination of programs. I started the initial drawing in Adobe Illustrator (Macintosh version 3.0, Copyright 1987-90 Adobe Systems Incorporated) and then transferred that image to Adobe Photoshop (Macintosh version 1.0, Copyright 1989-90 Adobe Systems Incorporated) where, using a combination of fills and patterns and filters, I created texture and three-dimensionality (Fig. 15). At times, I also used Macromind Director (Macintosh version 2.0, Copyright 1990 Adobe Systems Incorporated) because I preferred some aspects of its fill function.

The third section of my exhibit was similar in form and described the distribution of neuroleptic medication particularly through the blood-brain barrier. One of the illustrations from this section provided source material for all the rest of the Adobe Photoshop 1.0 images I created. That image was generated, as described before, by initially creating drawings in Adobe Illustrator 3.0 and then transporting them to Adobe Photoshop 1.0 where I manipulated them and overlaid them in layers into my final illustration (Fig. 16). Background imagery for my other illustrations, however, was derived from this image by copying an approximately one-half inch to one inch square section and enlarging it to suit my purposes (Figs. 10-13, 15 and 17). I then refined the image using various filter functions and by drawing into it.

The distortions and accidents brought about by the enlargement and filtration process created an almost painterly textural feel, unattainable by any other computer procedure. I then added any remaining elements I might desire drawn in Adobe Illustrator 3.0.

All my Adobe Illustrator 3.0 pieces and those of my Adobe Photoshop 1.0 images which exceeded $8.5 \times 11$ inch dimensions were printed by a thermal wax transfer process on a QMS colorscript 100 printer. The remainder of the Adobe Photoshop 1.0 pieces were printed through a dye process on a Kodak XL 7700 
ease of correction and without the hassle of having to cut frisket.

My initial research into this subject matter was poorly directed. There are many complicated and conflicting theories regarding schizophrenia, and it is very difficult for someone with limited medical education such as myself to know where to start. Consequently, I believe much of my research time was wasted until I finally consulted with Dr. Lamberti of Strong Memorial Hospital, only about four months before my opening. Dr. Lamberti's enthusiasm and help were critical to getting me going on the right track with a theory that at once made sense and lent itself to illustration.

Schizophrenia is a disease which continues to be a subject of lively debate among researchers. Little of a concrete nature is really known about it. This has strongly affected my project, at once to my advantage and disadvantage. It has made things more difficult insofar as there is not a central body of evidence and theory agreed upon by the psychiatric and neurological community to work from. It has caused me to have to deal with the question of what to illustrate almost as much as how to illustrate it. As a professional illustrator, my job should be to help make the subject understandable rather than to judge the relative value of different theories.

The advantage has been that I have become involved in an exciting, growing area of research close to the ground floor. My unusual specialization may give me the researchoriented job opportunities I am really hoping for. It has also allowed me to explore an area that has been of great personal interest to me, since several people I have known have become schizophrenic or have schizophrenic relatives. It was helpful to be able to connect the observations made by researchers with my own experience of schizophrenic patients. I think that this project has helped me achieve a much greater understanding of how these people are afflicted.

\section{REFERENCES}

1. Lori L. Altshuler, M.D., ManuelF. Casanova, M.D., Terry E. Goldberg, PhD., JoelE. Kleinman, M.D., PhD., "The Hippocampus and Parahippocampus in Schizophrenic, Suicide, and Control Brains," Archives of General Psychiatry 47 (November 1990): 1029-34.

2. American Psychiatric Association, Work Group to Revise DSM-III, Diagnostic and statistical manual of mental disorders: DSM-III- 
$\underline{\text { R } 3 r d ~ e d ., ~ r e v ., ~(W a s h i n g t o n, ~ D . C .: ~ A m e r i c a n ~}$ Psychiatric Association, 1987).

3. Steven E. Arnold, M.D., Bradley T. Hyman, M.D., PhD., Gary W. Van Hoesen, PhD., Antonio R. Damosio, M.D., PhD., "Some Cytoarchitectural Abnormalities of the Entorhinal Cortex in Schizophrenia," Archives of General Psychiatry 48 (July 1991): 625-32.

4. Karen Faith Berman, DanielR. Weinberger, "Lateralisation of cortical function during cognitive tasks: regional cerebral blood flow studies of normal individuals and patients with schizophrenia," Journal of Neurology. Neurosurgery \& Psychiatry 53, No. 2 (February 1990): 150-60.

5. Andrew J. Conrad, Arnold B. Scheibel, "Schizophrenia and the Hippocampus: The Embryological Hypothesis Extended," Schizophrenia Bulletin 13, No. 4 (1987): 577 87.

6. Larry Ereshefsky, Tram K. Tran-Johnson, and Mark D. Watanabe, "Pathophysiologic basis for schizophrenia and the efficacy of antipsychotics," Clinical Pharmacy 9 (September 1990): 682-702.

7. Dave L. Felton, John R. Sladek, Jr., "Monoamine Distribution in Primate Brain V. Monoaminergic Nuclei:Anatomy, Pathways and
Local Organization," Brain Research Bulletin 10, No. 2 (February 1983): 171-284.

8. Thomas M. Hyde, M.D., PhD., Daniel R. Weinberger, M.D., "The Brain in Schizophrenia," Seminars in Neurology 10, No. 3 (September 1990): 276-86.

9. Eric R. Kandel, M.D., James H. Schwartz, M.D., PhD., Principles of Neural Science 2nd ed.

(New York, N.Y.: Elsevier Science Publishing Co., Inc., 1985).

10. R.H. Kelly, R. Ganguli, B.S. Rabin, "Antibody to discrete area of the brain in normal individuals and patients with schizophrenia," Biological Psychiatry 22, No. 12 (December 1987): 148891.

11. Daniel J. Luchins, "A Possible Role of Hippocampal Dysfunction in Schizophrenic Symptomatology," Biological Psychiatry 28 (1990): 87-91.

12. Elaine N. Marieb, Human Anatomy and Physiology, (Redwood City, Ca.:The Benjamin/ Cummings Publishing Company, Inc., 1989). 13. Michael Miran, PhD., interview by author, Rochester, N.Y., 7 November 1991.

14. C.J. Pycock, R.W. Kerwin, C.J. Carter, "Effect of lesion of cortical dopamine terminals on subcortical dopamine in rats," Nature 286 (July 3, 1980): 74-6. 
15. Gavin P. Reynolds, Carole Czudek, Harry B. Andrews, "Deficit and Hemispheric Asymmetry of GABA Uptake Sites in the Hippocampus in Schizophrenia," Biological Psychiatry 27, No. 9 (May 1, 1990): 1038-44. 16. Melville Roberts, B.S., M.D., Joseph Hanaway, A.B., M.D., Atlas of the Human Brain in Section (Philadelphia, Pa.: Lea \& Febiger, 1970).

17. MichaelH. Ross, Lynn J. Romrell, Histology: A Text and Atlas 2nd ed. (Baltimore, Md.: Williams \& Witkins, 1989): 133-52.

18. Philip Seeman, "Dopamine Receptors and the Dopamine Hypothesis of Schizophrenia," Synapse 1 (1987).

19. Philip Seeman, "Dopamine receptors and transporters in Parkinson's disease and schizophrenia," The FASEB Journal 4, No. 10 (July 1990): 2737-44.

20. Philip Seeman, Hyman B. Niznik, H.C. Guan, Gillian Booth, Carla Ulpian, "Link between D, and $D_{2}$ dopamine receptors is reduced in schizophrenia and Huntington diseased brain," Processions of the National Academy of Science 86 (December 1989): 10156-60.

21. Szasz, Thomas Stephen, The Myth of Mental IIIness: foundations of a theory of personal conduct (New York, N.Y.: Harper \&
Row Publishers, Inc., 1974).

22. J.B. van Bree, A.G. de Boer, M. Danhof, L.A. Ginsel, D.D. Breimer, "Characterization of an 'in vitro' blood-brain barrier: effects of molecular size and lipophilicity on cerebrovascular endothelial transport rates of drugs," Journal of Pharmacology \& Experimental Therapeutics 247, No. 3 (December 1988): 1233-9.

23. Daniel R. Weinberger, M.D., "Implications of Normal Brain Development for the Pathogenesis of Schizophrenia," Archives of General Psychiatry 44 (July 1987): 660-9.

\section{FOOTNOTES}

1. Eric R. Kandel, M.D., James H. Schwartz, M.D., PhD., Principles of Neural Science 2 nd ed. (New York, N.Y.: Elsevier Science Publishing Co., Inc., 1985), 13.

2. Szasz, Thomas Stephen, The Myth of Mental Illness: foundations of a theory of personal conduct (New York, N.Y.: Harper \& Row Publishers, Inc., 1974), 152-3.

3. Larry Ereshefsky, Tram K. Tran-Johnson, and Mark D. Watanabe, "Pathophysiologic basis for schizophrenia and the efficacy of antipsychotics," Clinical Pharmacy 9 (September 1990), 684. 
4. Ibid.

5. Daniel J. Luchins, "A Possible Role of Hippocampal Dysfunction in Schizophrenic Symptomatology," Biological Psychiatry 28 (1990), 87-8.

6. American Psychiatric Association, Work Group to Revise DSM-III, Diagnostic and statistical manual of mental disorders: DSM-IIIR 3rd ed., rev., (Washington, D.C.: American Psychiatric Association, 1987), 187-98.

7. Ereshefsky, "Pathophysiologic basis for schizophrenia," 683.

8. Ibid.

9. Daniel R. Weinberger, M.D., "Implications of Normal Brain Development for the Pathogenesis of Schizophrenia," Archives of General Psychiatry 44 (July 1987), 660.

10. Lori L. Altshuler, M.D., ManuelF. Casanova, M.D., Terry E. Goldberg, PhD., JoelE. Kleinman, M.D., PhD., "The Hippocampus and Parahippocampus in Schizophrenic, Suicide, and Control Brains," Archives of General Psychiatry 47 (November 1990), 1029.

11. Karen Faith Berman, DanielR. Weinberger, "Lateralisation of cortical function during cognitive tasks: regional cerebral blood flow studies of normal individuals and patients with schizophrenia," Journal of Neurology.
Neurosurgery \& Psychiatry 53, No. 2 (February 1990), 150.

12. Altshuler, "The Hippocampus and Parahippocampus," 1032.

13. Philip Seeman, "Dopamine Receptors and the Dopamine Hypothesis of Schizophrenia," Synapse 1 (1987), 133.

14. Andrew J. Conrad, Arnold B. Scheibel, "Schizophrenia and the Hippocampus: The Embryological Hypothesis Extended," Schizophrenia Bulletin 13, No. 4 (1987), 579. 15. Steven E. Arnold, M.D., Bradley T. Hyman, M.D., PhD., Gary W. Van Hoesen, PhD., Antonio R. Damosio, M.D., PhD., "Some Cytoarchitectural Abnormalities of the Entorhinal Cortex in Schizophrenia," Archives of General Psychiatry 48 (July 1991), 628.

16. Altshuler, "The Hippocampus and Parahippocampus," 1031.

17. Weinberger, "Implications of Normal Brain Development," 661.

18. Ibid., 661-2.

19. Ibid., 665.

20. Dave L. Felton, John R. Sladek, Jr., "Monoamine Distribution in Primate Brain V. Monoaminergic Nuclei:Anatomy, Pathways and Local Organization," Brain Research Bulletin 10, No. 2 (February 1983), 188. 
21. C.J. Pycock, R.W. Kerwin, C.J. Carter, 1235.

"Effect of lesion of cortical dopamine , 74-7.

22. Weinberger, "Implications of Normal Brain Development," 661.

23. Ibid.

24. Ibid., 664.

25. Ibid., 665.

26. Ibid.

27. Ibid., 666 .

28. Ibid., 663.

29. R.H. Kelly, R. Ganguli, B.S. Rabin, “Antibody to discrete area of the brain in normal individuals and patients with schizophrenia," Biological Psychiatry 22, No. 12 (December 1987), 1489. 30. Weinberger, "Implications of Normal Brain Development," 665.

31. Ibid.

32. MichaelH. Ross, Lynn J. Romrell, Histology: A Text and Atlas 2nd ed. (Baltimore, Md.: Williams \& Witkins, 1989), 241.

33. Ibid.

34. J.B. van Bree, A.G. de Boer, M. Danhof, L.A. Ginsel, D.D. Breimer, "Characterization of an 'in vitro' blood-brain barrier: effects of molecular size and lipophilicity on cerebrovascular endothelial transport rates of drugs," Journal of Pharmacology \& Experimental Therapeutics 247, No. 3 (December 1988),
35. Philip Seeman, Hyman B. Niznik, H.C. Guan, Gillian Booth, Carla Ulpian, "Link between $D_{\text {, }}$ and $D_{2}$ dopamine receptors is reduced in schizophrenia and Huntington diseased brain," Processions of the National Academy of Science 86 (December 1989), 10156.

36. Idem, "Dopamine Receptors and the Dopamine Hypothesis of Schizophrenia," 137. 37. Thomas M. Hyde, M.D., PhD., Daniel R. Weinberger, M.D., "The Brain in Schizophrenia," Seminars in Neurology 10, No. 3 (September 1990), 282.

38. van Bree, 'Characterization of an 'in vitro' blood-brain barrier," 1235.

39. Elaine N. Marieb, Human Anatomy and Physiology, (Redwood City, Ca.:The Benjamin/ Cummings Publishing Company, Inc., 1989), 366.

40. Philip Seeman, "Dopamine receptors and transporters in Parkinson's disease and schizophrenia," The FASEB Journal 4, No. 10 (July 1990), 2742.

41. Marieb, Human Anatomy and Physiology, 534-5.

42. Ereshefsky, "Pathophysiologic basis for schizophrenia," 687.

43. Arnold, "Some Cytoarchitectural 
Abnormalities of the Entorhinal Cortex," 628.

44. Ibid.

45. Ibid.

46. Conrad, "Schizophrenia and the Hippocampus," 579.

47. Luchins, "A Possible Role of Hippocampal Dysfunction," 87-8.

48. Marieb, Human Anatomy and Physiology, 480-1.

49. Altshuler, "The Hippocampus and Parahippocampus," 1029.

50. Michael Miran, PhD., interview by author, Rochester, N.Y., 7 November 1991.

51. Ibid.

52. Ibid.

53. Conrad, "Schizophrenia and the Hippocampus," 582.

54. Ibid., 584.

55. Ibid., 583.

56. Ibid.

57. Marieb, Human Anatomy and Physiology, 534-5.

58. Gavin P. Reynolds, Carole Czudek, Harry B. Andrews, "Deficit and Hemispheric Asymmetry of GABA Uptake Sites in the Hippocampus in Schizophrenia," Biological Psychiatry 27, No. 9 (May 1, 1990), 1038.

59. Michael Miran, PhD., interview by author,
Rochester, N.Y., 7 November 1991.

60. Melville Roberts, B.S., M.D., Joseph Hanaway, A.B., M.D., Atlas of the Human Brain in Section (Philadelphia, Pa.: Lea \& Febiger, 1970)., 43, 69,79.

61. Felton, "Monoamine Distribution in Primate Brain V.," 188. 